\title{
RESEARCH
}

Open Access

\section{Influence of inflammatory conditions provided by macrophages on osteogenic ability of mesenchymal stem cells}

Gema Vallés ${ }^{1,2}$, Fátima Bensiamar ${ }^{1,2}$, Leila Maestro-Paramio ${ }^{1}$, Eduardo García-Rey ${ }^{2,3}$, Nuria Vilaboa ${ }^{1,2}$ and Laura Saldaña $a^{1,2^{*}}$ (iD

\begin{abstract}
Background: The mechanisms by which macrophage phenotype contributes to mesenchymal stem cells (MSC)mediated bone repair remain unclear. In this work, we investigated the influence of factors released by human macrophages polarized to a pro-inflammatory or an anti-inflammatory phenotype on the ability of human MSC to attach, migrate, and differentiate toward the osteoblastic lineage. We focused on the role of TNF-a and IL-10, key pro-inflammatory and anti-inflammatory cytokines, respectively, in regulating MSC functions.
\end{abstract}

Methods: MSC were treated with media conditioned by pro-inflammatory or anti-inflammatory macrophages to study their influence in cell attachment, migration, and osteogenic differentiation. The involvement of TNF-a and IL10 in the regulation of MSC functions was investigated using neutralizing antibodies and recombinant cytokines.

Results: Treatment of MSC with media conditioned by pro-inflammatory or anti-inflammatory macrophages promoted cell elongation and enhanced MSC ability to attach and migrate. These effects were more noticeable when MSC were treated with media from pro-inflammatory macrophages. Interestingly, MSC osteogenic activity was enhanced by factors released by anti-inflammatory macrophages, but not by pro-inflammatory macrophages. Significant IL-10 levels originated from anti-inflammatory macrophages enhanced MSC osteogenesis by increasing ALP activity and mineralization in MSC layers cultured under osteogenic conditions. Moreover, macrophage-derived IL-10 regulated the expression of the osteogenic markers RUNX2, COL1A1, and ALPL. Notably, low TNF-a levels secreted by anti-inflammatory macrophages increased ALP activity in differentiating MSC whereas high TNF-a levels produced by pro-inflammatory macrophages had no effects on osteogenesis. Experiments in which MSC were treated with cytokines revealed that IL-10 was more effective in promoting matrix maturation and mineralization than TNF-a.

Conclusions: Factors secreted by pro-inflammatory macrophages substantially increased MSC attachment and migration whereas those released by anti-inflammatory macrophages enhanced MSC osteogenic activity as well as cell migration. IL-10 was identified as an important cytokine secreted by anti-inflammatory macrophages that potentiates MSC osteogenesis. Our findings provide novel insights into how environments provided by macrophages regulate MSC osteogenesis, which may be helpful to develop strategies to enhance bone regeneration.

Keywords: Mesenchymal stem cells, Osteogenesis, Migration, Attachment, Macrophage polarization, Cytokines

\footnotetext{
*Correspondence: laura.saldana@salud.madrid.org

${ }^{1}$ Hospital Universitario La Paz. IdiPAZ, Paseo de la Castellana 261, 28046

Madrid, Spain

${ }^{2}$ Centro de Investigación Biomédica en Red de Bioingeniería, Biomateriales y

Nanomedicina, CIBER-BBN, Madrid, Spain

Full list of author information is available at the end of the article
}

(c) The Author(s). 2020 Open Access This article is distributed under the terms of the Creative Commons Attribution 4.0 International License (http://creativecommons.org/licenses/by/4.0/), which permits unrestricted use, distribution, and reproduction in any medium, provided you give appropriate credit to the original author(s) and the source, provide a link to the Creative Commons license, and indicate if changes were made. The Creative Commons Public Domain Dedication waiver (http://creativecommons.org/publicdomain/zero/1.0/) applies to the data made available in this article, unless otherwise stated. 


\section{Introduction}

Inflammatory response mediated by macrophages plays a vital role in fracture healing $[1,2]$. Upon bone injury, monocytes are recruited to the wound site and differentiate into activated macrophages, a major source of cytokines involved in bone repair and regeneration. Macrophage populations can adopt differential functional profiles ranging from the pro-inflammatory polarization state M1 to the anti-inflammatory M2. In the initial phase of inflammation, M1-type macrophages secrete high amounts of proinflammatory cytokines such as tumor necrosis factoralpha (TNF- $\alpha$ ). TNF- $\alpha$, a primary mediator in the inflammatory reaction, promotes the recruitment of inflammatory and stromal cells, stimulates angiogenesis and is essential for bone fracture repair, as demonstrated in TNF- $\alpha$ receptor-deficient mice $[3,4]$. In the later stages of inflammation, M2-type macrophages secrete anti-inflammatory cytokines and growth factors, which mediate the resolution of inflammation and tissue repair. Among them, interleukin-10 (IL-10) is a key anti-inflammatory cytokine in the bone regenerative process. IL-10-deficient mice display osteopenia, mechanical fragility of bones, and decreased bone formation [5]. The outcome of bone repair is tightly regulated by the inflammatory milieu, leading the imbalance between proinflammatory and anti-inflammatory cytokines during bone healing to chronic inflammation, aberrant bone repair, or excessive ossification.

The early step of bone formation involves the migration of mesenchymal stem cells (MSC), which undergo proliferation and differentiation along the osteoblastic lineage. Indeed, MSC implantation has emerged as a promising strategy for promoting bone regeneration in several clinical conditions, including delayed unions and non-unions, critical-sized bone defects, periprosthetic osteolysis, osteonecrosis, and inflammatory bone disorders [6-10]. The benefits of MSC therapy are mainly attributed to paracrine effects via soluble factors, exerting both immunoregulatory and regenerative actions [11]. Although implanted MSC may act as osteoprogenitors [12-14], most evidence indicates that newly formed bone is mainly derived from host progenitors. The mechanisms by which macrophages contribute to MSC-mediated tissue repair remain unclear. TNF- $\alpha$, which is highly expressed in macrophages during the early inflammatory phase after fracture [15], promotes MSC migration and plays an important role in the activation of MSC immunoregulatory properties [16-18]. Moreover, pro-inflammatory cytokines can directly impact MSC commitment to the osteoblastic lineage. Thus, TNF$\alpha$ contained in supernatants from human fractured tibial bone enhances MSC osteogenic differentiation in vitro [19]. Further studies using recombinant TNF- $\alpha$ show that its effect on MSC osteogenesis depends on the dose and the length of treatment [19-23]. Regarding antiinflammatory cytokines, their effects on bone healing have been largely explained by their ability to inhibit the production of pro-inflammatory factors by macrophages [24]. However, very little attention has focused on their direct effects on MSC. We recently reported that IL-10 originated from pro-resolving macrophages enhances MSC immunomodulatory potential in vitro [18]. In addition, a recent study showed that physiological doses of recombinant IL-10 stimulate MSC osteogenic differentiation while higher pathological doses inhibit it [25].

In the present study, we investigated the influence of factors produced by human macrophages polarized to a proinflammatory or an anti-inflammatory phenotype on the ability of MSC to attach, migrate, and differentiate toward the osteoblastic lineage. We focused on the role of TNF- $\alpha$ and IL-10, key pro-inflammatory and anti-inflammatory cytokines, respectively, in regulating MSC functions.

\section{Methods}

Isolation and culture of primary human macrophages Buffy coats were obtained from 15 healthy blood donors anonymously provided by the Comunidad de Madrid Blood Bank (Madrid, Spain). This study was approved by the Human Research Committee of Hospital Universitario La Paz (date of approval 03/06/2015). All experiments were carried out in accordance with the approved guidelines and regulations. Human peripheral blood mononuclear cells (PBMC) were isolated from buffy coats by Ficoll-Paque Plus (GE Healthcare Bio-sciences, Uppsala, Sweden) density gradient centrifugation. PBMC were seeded at a density of $15 \times 10^{6} /$ well in 6-well plates and allowed to adhere for $1 \mathrm{~h}$ in serum-free RPMI (Lonza, Basel, Switzerland). Attached cells were incubated for 7 days in RPMI supplemented with $10 \%(\mathrm{v} / \mathrm{v})$ heat-inactivated fetal bovine serum (FBS) and $200 \mathrm{U} / \mathrm{ml}$ granulocyte macrophage colony-stimulating factor (GM-CSF) or 20 $\mathrm{ng} / \mathrm{ml}$ macrophage colony-stimulating factor (M-CSF) (both from Peprotech, London, UK). Cytokines were added every 2 days. Macrophages generated after incubation with GM-CSF $\left(M \Phi_{\mathrm{GM}}\right)$ expressed the M1 markers CD80 and CCR7 while they were devoid of the cellsurface receptor CD163, a marker of M2 macrophages. In contrast, macrophages generated after incubation with $\mathrm{M}$ CSF $\left(M \Phi_{M}\right)$ expressed high levels of CD163 and very low levels of CD80 and CCR7 [18]. Conditioned medium $(\mathrm{CM})$ was obtained from $\mathrm{M} \Phi_{\mathrm{GM}}$ and $\mathrm{M} \Phi_{\mathrm{M}}$ treated $\left(\mathrm{CM}_{\mathrm{GM}+}\right.$ and $\mathrm{CM}_{\mathrm{M}+}$, respectively) or not $\left(\mathrm{CM}_{\mathrm{GM}-}\right.$ and

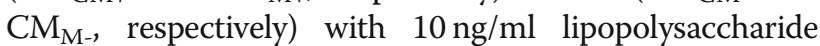
(LPS) (Sigma, Madrid, Spain) for $90 \mathrm{~min}$, washed three times with phosphate-buffered saline (PBS) and cultured for $5 \mathrm{~h}$ in RPMI supplemented with 10\% FBS in the absence of LPS. The experimental scheme used to generate $\mathrm{CM}$ is shown in Fig. 1a. CM was clarified by centrifugation at $1200 \mathrm{~g}$ for $10 \mathrm{~min}$. Levels of TNF- $\alpha$, IL-6, IL-1 $\beta$, IL-10, IL-8, and monocyte chemoattractant protein-1 (MCP-1) 
a

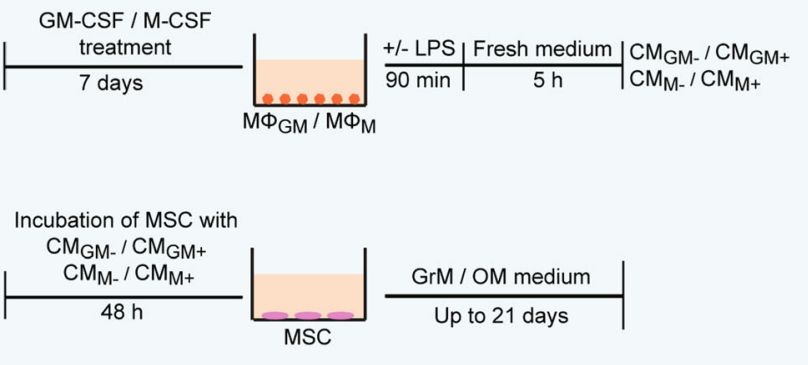

b
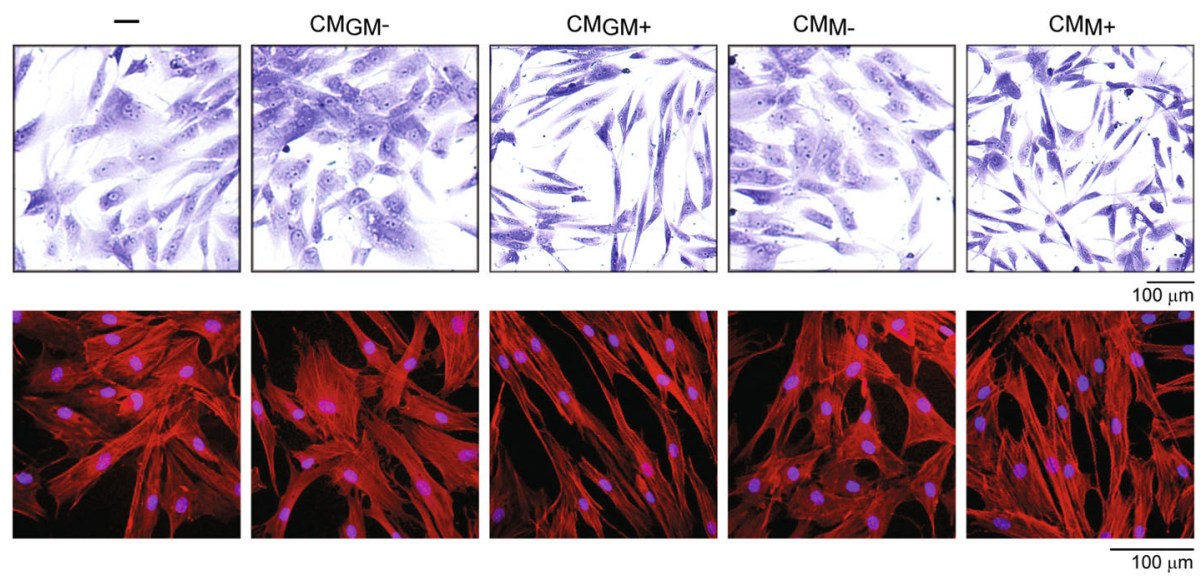

C

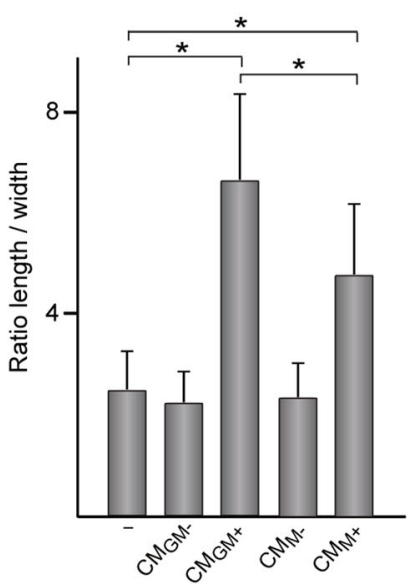

Fig. 1 Morphology of MSC treated with CM. a Experimental scheme used for generating conditioned medium (CM) from macrophages and for MSC treatments. $C M_{G M+}$ and $C M_{M+}$ were obtained from $M \Phi_{G M}$ and $M \Phi_{M}$, respectively, that were treated with LPS for 90 min, thoroughly washed with PBS, and further incubated in fresh medium for $5 \mathrm{~h}$. $C M_{G M}$ - and $C M_{M-}$ were obtained from $M \Phi_{G M}$ and $M \Phi_{M}$, respectively, that were not treated with LPS but subjected to identical experimental manipulations. MSC were incubated or not with CM for $48 \mathrm{~h}$, thoroughly washed with PBS, and further incubated in growth (GrM) or osteogenic (OM) medium up to 21 days. b Optical microscope images showing the morphology of MSC treated or not (-) with CM after crystal violet staining (upper row). Confocal microscope images (maximum projection) showing actin (red) and nuclei (blue) in MSC treated or not with CM (lower row). c Ratio of cell length to width as measure of cell elongation. ${ }^{*} p<0.05$ between the indicated conditions 
in CM were determined using BD CBA Flex Sets (BD Biosciences, San Jose, CA, USA). The data were acquired using a FACSCalibur flow cytometer and analyzed with the FCAP Array Software version 3.0 (BD Biosciences). The detection limits were $3.7 \mathrm{pg} / \mathrm{ml}$ for TNF- $\alpha, 2.5 \mathrm{pg} / \mathrm{ml}$ for IL-6, $2.6 \mathrm{pg} / \mathrm{ml}$ for IL- $1 \beta, 3.3 \mathrm{pg} / \mathrm{ml}$ for IL-10, $1.2 \mathrm{pg} /$ $\mathrm{ml}$ for IL-8, and $1.3 \mathrm{pg} / \mathrm{ml}$ for MCP-1.

\section{MSC culture and treatments}

Human MSC derived from bone marrow were purchased from Lonza and expanded in a defined growth medium consisting of basal medium and supplements (Lonza). All experiments were performed below the seventh cell passage. Experiments were performed in duplicate using MSC isolated from five different donors aged 18-31 years. MSC were incubated for $48 \mathrm{~h}$ in DMEM supplemented with $15 \%(\mathrm{v} / \mathrm{v})$ heat-inactivated FBS (growth medium) or in a mixture of equal volumes of growth medium and $\mathrm{CM}$. When indicated, and prior to addition to MSC, CM was incubated for $1 \mathrm{~h}$ at $37^{\circ} \mathrm{C}$ with $1 \mu \mathrm{g} / \mathrm{ml}$ neutralizing antibody against TNF- $\alpha$ or IL-10 (Biolegend, San Diego, CA, USA). In some experiments, MSC were incubated in growth medium containing human TNF- $\alpha$ or IL-10 at 0.1, 1 , or $10 \mathrm{ng} / \mathrm{ml}$ (Peprotech). This concentration range was selected according to TNF- $\alpha$ and IL-10 levels in $\mathrm{CM}_{\mathrm{GM}+}$ or $\mathrm{CM}_{\mathrm{M}+}$. In differentiation assays, MSC treated with $\mathrm{CM}$ or cytokines were washed three times with PBS and incubated in osteogenic medium consisting of growth medium supplemented with $3 \times 10^{-4} \mathrm{M}$ ascorbic acid, $10^{-2} \mathrm{M} \beta$ glycerophosphate, and $10^{-7} \mathrm{M}$ of dexamethasone (all from Sigma) for 3-21 days. As controls, untreated cells were incubated in the growth medium. The experimental scheme is shown in Fig. 1a.

\section{Cell morphology, attachment, and migration}

To analyze cell morphology, $2 \times 10^{4}$ MSC were seeded in 8 -well chamber slides and incubated for $48 \mathrm{~h}$ in $200 \mu \mathrm{l}$ of a mixture of equal volumes of growth medium and $\mathrm{CM}$ or in $200 \mu \mathrm{l}$ of growth medium supplemented or not with the indicated cytokines. Cells were washed with PBS, stained with crystal violet, and observed under a phase-contrast microscope (Nikon Diaphot, Tokio, Japan). Cell elongation was determined by analyzing a total of 100 cells per condition, randomly selected from 6 representative images obtained from 3 independent experiments with similar results. Cells were manually outlined using ImageJ v1.34 image analysis software (http://rsbweb.nih.gov/ij), which fits each cell to the fittest ellipse. The lengths of the major and the minor axis of the fittest ellipse correspond to cell length and width, respectively. Elongation was defined as the ratio of the major axis to the minor axis. Parallel sets of cells were fixed with $4 \%(\mathrm{w} / \mathrm{v})$ formaldehyde in PBS, permeabilized with $0.1 \%$ Triton X-100 in PBS and doublestained with PBS containing $4 \times 10^{-7} \mathrm{M}$ phalloidine- tetramethylrhodamine (TRITC) (Sigma) and $3 \times 10^{-6} \mathrm{M} 4$, 6-diamidino-2-phenylindole (DAPI, Sigma). Images of fluorescently stained cells were obtained using a Leica TCS SPE confocal microscope (Wetzlar, Germany).

For cell attachment assays, $10^{6}$ MSC were seeded in $100 \mathrm{~mm}$ diameter culture dishes and incubated for $48 \mathrm{~h}$ in $10 \mathrm{ml}$ of a mixture of equal volumes of growth medium and $\mathrm{CM}$ or in $10 \mathrm{ml}$ of growth medium supplemented or not with the indicated cytokines. Cells were detached and seeded at a density of $10^{5} /$ well in 24 -well plates for $0.5,1,2$, or $3 \mathrm{~h}$ in growth medium. After washing extensively with PBS, attached cells were trypsinized and the number of live cells at each time point was quantified by the trypan blue dye exclusion method. To determine cell migration, $2 \times 10^{4}$ MSC were seeded on tissue culture plastic surfaces confined within squared silicone barriers (Flexiperm, Sigma) placed in 6-well plates and incubated for $48 \mathrm{~h}$ in $200 \mu \mathrm{l}$ of a mixture of equal volumes of growth medium and $\mathrm{CM}$ or in $200 \mu \mathrm{l}$ of growth medium. After washing three times with PBS, the silicon barrier was removed, allowing cells to migrate, and cultures were incubated for 5 days in growth medium. Cells were subsequently stained with crystal violet and observed under a phase-contrast microscope. In some experiments, MSC were incubated in growth medium supplemented with human TNF- $\alpha$ or IL-10 at $1 \mathrm{ng} / \mathrm{ml}$ or with IL-10 at $10 \mathrm{ng} / \mathrm{ml}$ and cell attachment and migration were determined as described above.

\section{Cell viability}

$10^{5}$ MSC were seeded in 12-well plates and incubated for $48 \mathrm{~h}$ in $1 \mathrm{ml}$ of a mixture of equal volumes of growth medium and CM or in $1 \mathrm{ml}$ of growth medium supplemented or not with the indicated cytokines. After washing three times with PBS, MSC were incubated for 1, 3, and 7 days in growth medium. Cell viability was determined using the alamarBlue assay (Biosource, Nivelles, Belgium). Briefly, MSC were incubated in DMEM containing $10 \%$ alamarBlue dye for $3 \mathrm{~h}$ and the fluorescence emitted by cell-reduced alamarBlue was quantified using a spectrofluorimeter (Synergy4, Evry, France).

\section{ALP activity and cell layer calcification assays}

$2 \times 10^{5}$ MSC were seeded in 6-well plates and incubated for $48 \mathrm{~h}$ in $2 \mathrm{ml}$ of a mixture of equal volumes of growth medium and $\mathrm{CM}$ or in $2 \mathrm{ml}$ of growth medium supplemented or not with the indicated cytokines. After washing with PBS, MSC were induced to undergo differentiation by incubation in osteogenic medium up to 21 days. As controls, untreated cells were incubated in growth medium. Media were partially replaced every 3 days. After 14 days of culture, cell layers were extracted with $5 \times 10^{-1}$ $\mathrm{M} \mathrm{NaCl}, 5 \times 10^{-2} \mathrm{M}$ Tris- $\mathrm{HCl} \mathrm{pH} 8.0$, and $1 \%$ Triton X100 and supplemented with a mixture of protease 
inhibitors. Alkaline phosphatase (ALP) activity was assessed in cell layers by determining the release of $\mathrm{p}$ nitrophenol from p-nitrophenyl phosphate (Sigma). The data were normalized to the total protein contents determined by a Bradford-based protein assay (Bio-Rad Laboratories Inc., Hercules, CA). The degree of cell layer calcification was assessed in cells cultured for 3-21 days using alizarin red staining. Briefly, cells were fixed with ethanol and stained with $40 \mathrm{mM}$ alizarin red $\mathrm{S}$ in deionized water at $\mathrm{pH}$ 4.2. Images of stained cell layers were obtained using a phase-contrast microscope. The bound stain was eluted with $10 \%(\mathrm{w} / \mathrm{v})$ cetylpyridinium chloride and the absorbance at $562 \mathrm{~nm}$ was measured using a spectrofluorometer.

\section{Gene expression}

$2 \times 10^{5}$ MSC were seeded on 6-well plates and incubated for $48 \mathrm{~h}$ in $2 \mathrm{ml}$ of a mixture of equal volumes of growth medium and $\mathrm{CM}$ or in $2 \mathrm{ml}$ of growth medium supplemented or not with the indicated cytokines. MSC were harvested immediately after treatment with $\mathrm{CM}$ or cytokines or after washing with PBS and further incubation in osteogenic medium for 3-21 days. Total RNA was isolated using TRI Reagent (Molecular Research Center, Inc., Cincinnati, OH, USA). Complementary DNAs were prepared from total RNA using the Transcriptor Reverse Transcriptase and an anchored-oligo $(\mathrm{dT})_{18}$ primer (Roche Applied Science, Indianapolis, IN, USA). Real-time quantitative PCR was performed using the LightCycler FastStart DNA Master SYBR Green I and a LightCycler instrument (Roche). Quantitative expression values were extrapolated from standard curves and normalized to the expression values of glyceraldehyde 3phosphate dehydrogenase (GAPDH). Due to a lack of stability of GAPDH expression in cells incubated under osteogenic conditions, quantitative expression values from cells cultured in osteogenic medium were normalized to the mean of the expression values of hypoxanthine-guanine phosphoribosyltransferase (HPRT1) and beta-glucuronidase (GUSB). Specific oligonucleotide primers were runt-related transcription factor 2 (RUNX2), 5'-ATGATGACACTGCCACCTCTGA3' (forward primer, F), 5'-GGCTGGATAGTGCATTCG TG-3', (reverse primer, R); collagen type I alpha 1 (COL1A1), 5'-CGGGCCTCAAGGTATTGCT-3' (F) and 5'-GGGACC TTGTTTGCCAGGTT-3' (R); ALPL, 5' - GACTAAGAAG CCCTTCACTGCCAT-3' (F), 5' - GACTGCGCCTGGTA
GTTGTT-3' (R); GAPDH, 5'-GTGAAGGTCGGAGT CAACG-3' (F), 5'-GAAGATGGTGATGGGATTTCC3'(R); HPRT1，5'-ACCCCACGAAGTGTTGGATA-3' (F), 5'-AAGCAGATGGCCACAGAACT-3'(R) and GUSB, 5'AAACGATTGCAGGGTTTCAC-3' (F), 5'-CTCTCG TCGGTGACTGTTCA-3'(R).

\section{Statistical analysis}

The statistical analyses were performed using the Statistical Program for Social Sciences version 11.5 (SPSS Inc., Chicago, IL, USA). Experiments were carried out in duplicate and data are presented as means $\pm \mathrm{SD}$ of at least five independent experiments. Shapiro-Wilk and Kolmogorov-Smirnov normality tests were used to evaluate whether the data followed normal distribution. Quantitative data were tested using one-way analysis of variance (ANOVA) followed by Bonferroni's multiple comparison test or Kruskal-Wallis followed by Dunn's multiple comparison test, depending on whether the data were parametric or nonparametric, respectively. The level of significance was set to $p<0.05$.

\section{Results \\ Inflammatory factors secreted by macrophages affect MSC morphology, adhesion, and migration}

MSC were treated with $\mathrm{CM}$ from $M \Phi_{\mathrm{GM}}$ or $M \Phi_{\mathrm{M}}$ activated or not with LPS to examine the effects of inflammatory cytokines on MSC (Fig. 1a). First, we determined the concentrations in $\mathrm{CM}$ of some inflammatory factors whose levels are known to change during the inflammatory response subsequent to bone injury. $\mathrm{CM}_{\mathrm{GM}+}$ contained higher levels of the classical pro-inflammatory cytokines TNF- $\alpha$, IL- 6 , and IL- $1 \beta$ and lower levels of the anti-inflammatory cytokine IL-10 than $\mathrm{CM}_{\mathrm{M}_{+}}$(Table 1). Moreover, the levels of the inflammatory chemokines IL-8 and MCP-1 were higher in $\mathrm{CM}_{\mathrm{GM}+}$ than in $\mathrm{CM}_{\mathrm{M}_{+}}$. In contrast, IL-10 and IL-1 $\beta$ levels could not be detected in $\mathrm{CM}$ from non-activated $\mathrm{M} \Phi_{\mathrm{GM}}$ or $\mathrm{M} \Phi_{\mathrm{M}}$, which contained low concentrations of TNF- $\alpha$, IL-6, IL-8, and MCP-1 (Table 1). MSC treated for $48 \mathrm{~h}$ with CM from activated macrophages displayed a much more elongated morphology than untreated MSC (Fig. 1b, c). Cell elongation was more pronounced after treatment with $\mathrm{CM}_{\mathrm{GM}+}$ than with $\mathrm{CM}_{\mathrm{M}+}$ (Fig. 1c). The organization of actin cytoskeleton, involved in the acquisition of cell shape, showed

Table 1 Levels of inflammatory cytokines in conditioned medium from macrophages

\begin{tabular}{lllllll}
\hline & TNF- $a$ & IL-6 & IL-1 & IL-10 & IL-8 & MCP-1 \\
\hline $\mathrm{CM}_{\mathrm{GM}-}$ & $(5.81 \pm 1.11) \times 10^{-3}$ & $0.15 \pm 0.02$ & N.D. & N.D. & $0.10 \pm 0.02$ & $1.13 \pm 0.19$ \\
$\mathrm{CM}_{\mathrm{GM}+}$ & $14.16 \pm 3.92$ & $11.52 \pm 2.85$ & $0.12 \pm 0.02$ & $0.16 \pm 0.03$ & $5.22 \pm 1.57$ & $28.07 \pm 4.02$ \\
$\mathrm{CM}_{\mathrm{M}-}$ & $(5.89 \pm 1.32) \times 10^{-3}$ & $0.12 \pm 0.03$ & N.D. & N.D. & $0.03 \pm 0.01$ & $1.18 \pm 0.37$ \\
$\mathrm{CM}_{\mathrm{M}+}$ & $2.40 \pm 0.40$ & $2.10 \pm 0.59$ & $0.03 \pm 0.01$ & $2.58 \pm 0.48$ & $1.39 \pm 0.32$ & $11.05 \pm 2.91$ \\
\hline
\end{tabular}

Conditioned medium $(C M)$ was collected from $M \Phi_{G M}$ and $M \Phi_{M}$ treated $\left(\mathrm{CM}_{\mathrm{GM}+}\right.$ and $\mathrm{CM}_{\mathrm{M}_{+},}$respectively) or not $\left(\mathrm{CM}_{\mathrm{GM}-}\right.$ and $\mathrm{CM}_{\mathrm{M}-\text {, }}$ respectively) with $10 \mathrm{ng} / \mathrm{ml} \mathrm{LPS}$ for $90 \mathrm{~min}$ and incubated $5 \mathrm{~h}$ in fresh medium. The data are expressed as $\mathrm{ng} / \mathrm{ml}$ of culture medium. N.D. not detected 
differences in untreated and treated MSC. Actin bundles of MSC treated with $\mathrm{CM}_{\mathrm{GM}_{+}}$or $\mathrm{CM}_{\mathrm{M}_{+}}$organized in closely packed parallel arrays throughout the stretched cell body whereas actin filaments of untreated MSC were more loosely spaced (Fig. 1b). No differences in cell shape and elongation or in actin arrangement were found between MSC treated with CM from non-activated macrophages and untreated cells (Fig. 1b, c). To assess whether exposure to CM affects MSC attachment, cells were seeded on tissue culture plastic and subsequent cultured up to $3 \mathrm{~h}$. Attachment of MSC untreated and treated with CM from non-activated macrophages was similar (Fig. 2a). In contrast, the treatment of MSC with CM from activated macrophages increased cell attachment at all evaluated time points. The number of attached cells was higher when MSC were treated with $\mathrm{CM}_{\mathrm{GM}}$ than with $\mathrm{CM}_{\mathrm{M}_{+}}$. Viability of MSC incubated in growth medium up to 14 days was unaffected by CM treatment (Fig. 2b) Next, we determined whether factors secreted from macrophages regulate MSC migratory activity. Treatment with $\mathrm{CM}$ from activated macrophages increased MSC migration, being this effect higher in MSC treated with $\mathrm{CM}_{\mathrm{GM}_{+}}$than with $\mathrm{CM}_{\mathrm{M}_{+}}$(Fig. 2c). No effect on migratory activity was observed in cells treated with $\mathrm{CM}$ from non-activated macrophages. Together, these data indicate that CM from activated macrophages, which contains high levels of inflammatory mediators, promotes MSC elongation, and enhances MSC ability to attach and migrate. These effects were more noticeable when MSC were treated with $\mathrm{CM}_{\mathrm{GM}+}$ than with $\mathrm{CM}_{\mathrm{M}+}$.

\section{Inflammatory factors secreted by anti-inflammatory macrophages enhance MSC osteogenic potential}

Next, the effect of inflammatory factors secreted by $M \Phi_{\mathrm{GM}}$ or $M \Phi_{\mathrm{M}}$ on MSC osteogenic differentiation was investigated. We performed time-course experiments of ALP activity in MSC treated with CM for 24-96 h and further incubated in osteogenic media for 14 days. Treatment of MSC for $24 \mathrm{~h}$ with CM from macrophages, activated or not with LPS, did not lead to significant changes in ALP activity (Additional file 1: Figure S1). ALP activity was neither affected by the treatment of MSC for $48 \mathrm{~h}$ with CM from non-activated macrophages or with $\mathrm{CM}_{\mathrm{GM}+}$ (Fig. 3a). However, MSC treated for 48 $h$ with $\mathrm{CM}_{\mathrm{M}+}$ showed increased ALP activity as compared to untreated cells (Fig. 3a). Treatment of MSC with $\mathrm{CM}_{\mathrm{M}+}$ for $72 \mathrm{~h}$ also increased ALP activity, although to a lesser extent than treatment for $48 \mathrm{~h}$, whereas treatment for $96 \mathrm{~h}$ had no effect (Additional file 1: Figure S1). There was no alizarin red staining indicative of calcium deposits in layers of MSC cultured in osteogenic medium for 3-7 days (Additional file 1: Figure S2). Mineral deposits were visible in MSC layers after 14 days of incubation in osteogenic medium (Fig. 3b). As expected, alizarin red staining was more intense in MSC incubated for 21 than for 14days (Fig. 3b). At both time points, MSC treated with $\mathrm{CM}_{\mathrm{M}}$ showed higher mineralization degree than untreated cells (Fig. 3b).

We then determined whether treatment with inflammatory factors secreted by activated macrophages regulates the expression, at the mRNA level, of osteogenic markers in MSC. To this end, mRNA levels of RUNX2, COL1A1, and ALPL were quantified in MSC treated with $\mathrm{CM}$ for $48 \mathrm{~h}$. Treatment of MSC with CM from nonactivated macrophages did not affect transcript levels of any of the genes tested (Fig. 4a). However, MSC treated with $\mathrm{CM}_{\mathrm{M}+}$ showed higher RUNX2 mRNA levels than untreated cells (Fig. 4a). Treating MSC with $\mathrm{CM}_{\mathrm{GM}+}$ or $\mathrm{CM}_{\mathrm{M}+}$ led to a decrease in COL1A1 mRNA levels while ALPL mRNA levels remained unaffected (Fig. 4a). Next, we assessed whether treatment with $\mathrm{CM}$ modulates the expression of RUNX2, COL1A1, and ALPL in MSC further incubated in osteogenic medium. In general, the culture of MSC, treated or not with CM, in media with osteogenic inducers increased RUNX2 and ALPL mRNA levels while decreased the levels of COL1A1 transcripts (Fig. 4b). The expression of these genes in differentiating MSC was not affected by treatment with CM from nonactivated macrophages (data not shown). In contrast, RUNX2 mRNA levels in MSC treated with $\mathrm{CM}_{\mathrm{M}+}$ were higher than in untreated MSC at 3 days of differentiation. At this time point, COL1A1 mRNA levels in MSC treated with $\mathrm{CM}_{\mathrm{GM}+}$ or $\mathrm{CM}_{\mathrm{M}+}$ were lower than in untreated MSC. When incubation time extended to 7 or 14 days, there were no differences in RUNX2 or COL1A1 mRNA levels between MSC untreated and treated with CM (Fig. 4b). Interestingly, after 7 days of incubation in osteogenic medium, MSC treated with $\mathrm{CM}_{\mathrm{M}_{+}}$but not with $\mathrm{CM}_{\mathrm{GM}}$ showed higher ALPL mRNA levels than untreated MSC, whereas no changes were detected thereafter (Fig. $4 \mathrm{~b}$ ). Taking together, these results indicate that the expression of RUNX2, ALPL, and COL1A1 in MSC is regulated by factors contained in $\mathrm{CM}_{\mathrm{M}+}$, an effect associated with increased osteogenic ability.

\section{TNF- $a$ and IL-10 secreted by anti-inflammatory} macrophages are involved in enhanced MSC osteogenesis Treatment of MSC with $\mathrm{CM}_{\mathrm{M}_{+}}$, which contains higher levels of IL-10 and lower levels of TNF- $\alpha$ than $\mathrm{CM}_{\mathrm{GM}+}$, enhanced their osteogenic potential. To investigate whether MSC osteogenic differentiation is stimulated by TNF- $\alpha$ and IL-10 secreted by $M \Phi_{\mathrm{M}}$, MSC were treated for $48 \mathrm{~h}$ with $\mathrm{CM}_{\mathrm{M}+}$ that had been incubated with neutralizing TNF- $\alpha$ or IL-10 antibodies. Blocking IL-10 but not TNF- $\alpha$ attenuated the increase in RUNX2 mRNA levels induced by treatment with $\mathrm{CM}_{\mathrm{M}+}$ (Fig. 5a). Notably, COL1A1 mRNA levels in MSC treated with $\mathrm{CM}_{\mathrm{M}+}$ increased when TNF- $\alpha$ was blocked 

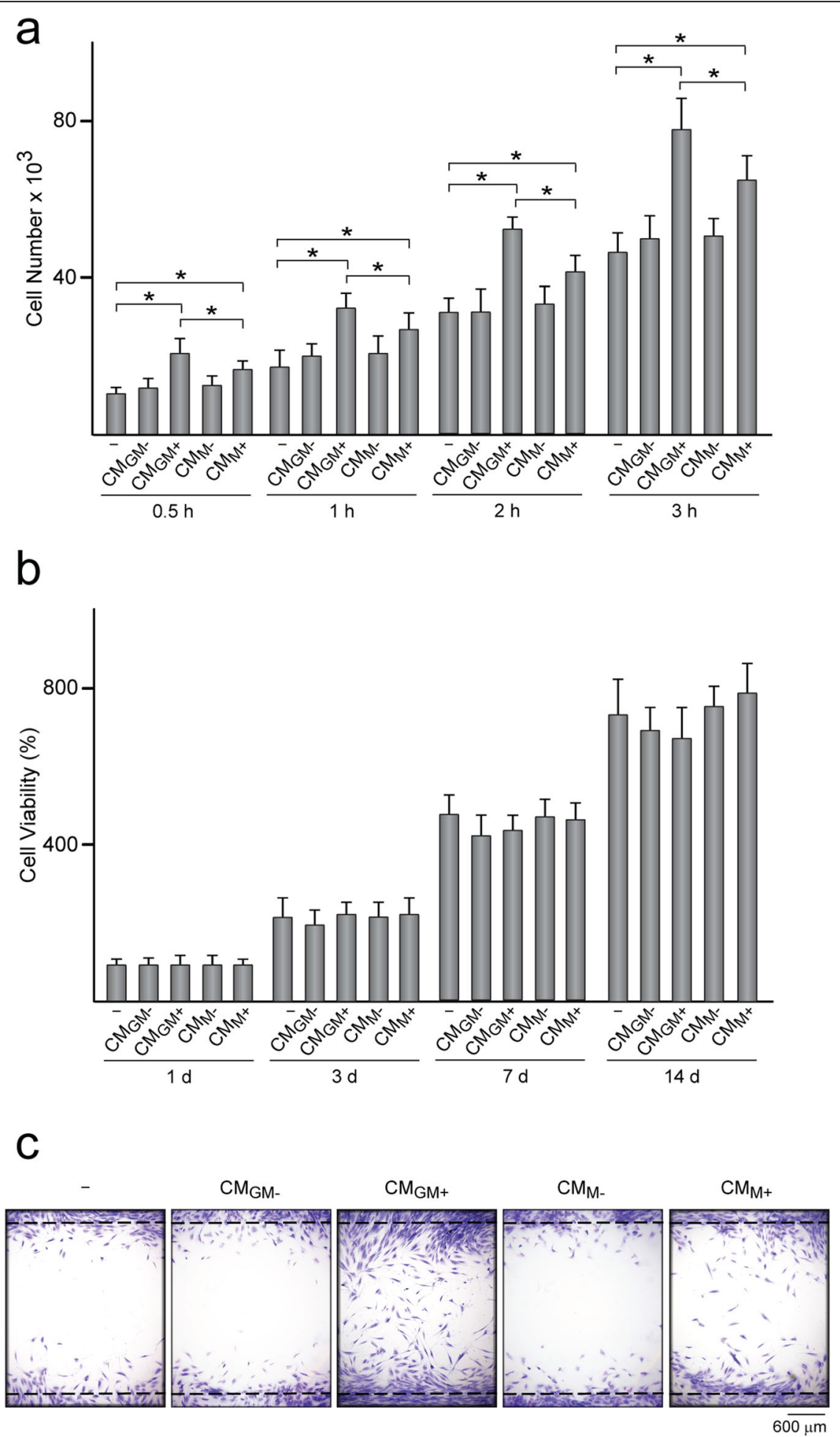

Fig. 2 Adhesion, viability and migration of MSC treated with CM. a Number of MSC treated or not (-) with $C M$ from $M \Phi_{G M}$ and $M \Phi_{M}$ activated $\left(C M_{G M+}\right.$ and $C M_{M+}$, respectively) or not $\left(C_{G_{M}-}\right.$ and $C M_{M-}$, respectively) with LPS and further incubated in growth media (GrM) for the indicated time points. $\mathbf{b}$ Viability of MSC treated or not with CM and further incubated in GrM for the indicated time points. The data are relative to those measured in each group at day 1, which were given an arbitrary value of 100. c Migration capacity of MSC seeded inside the area confined by squared silicone barriers, treated or not with CM and allowed to migrate for 5 days. Optical microscope images of cells stained with crystal violet. ${ }^{*} p<0.05$ between the indicated conditions 

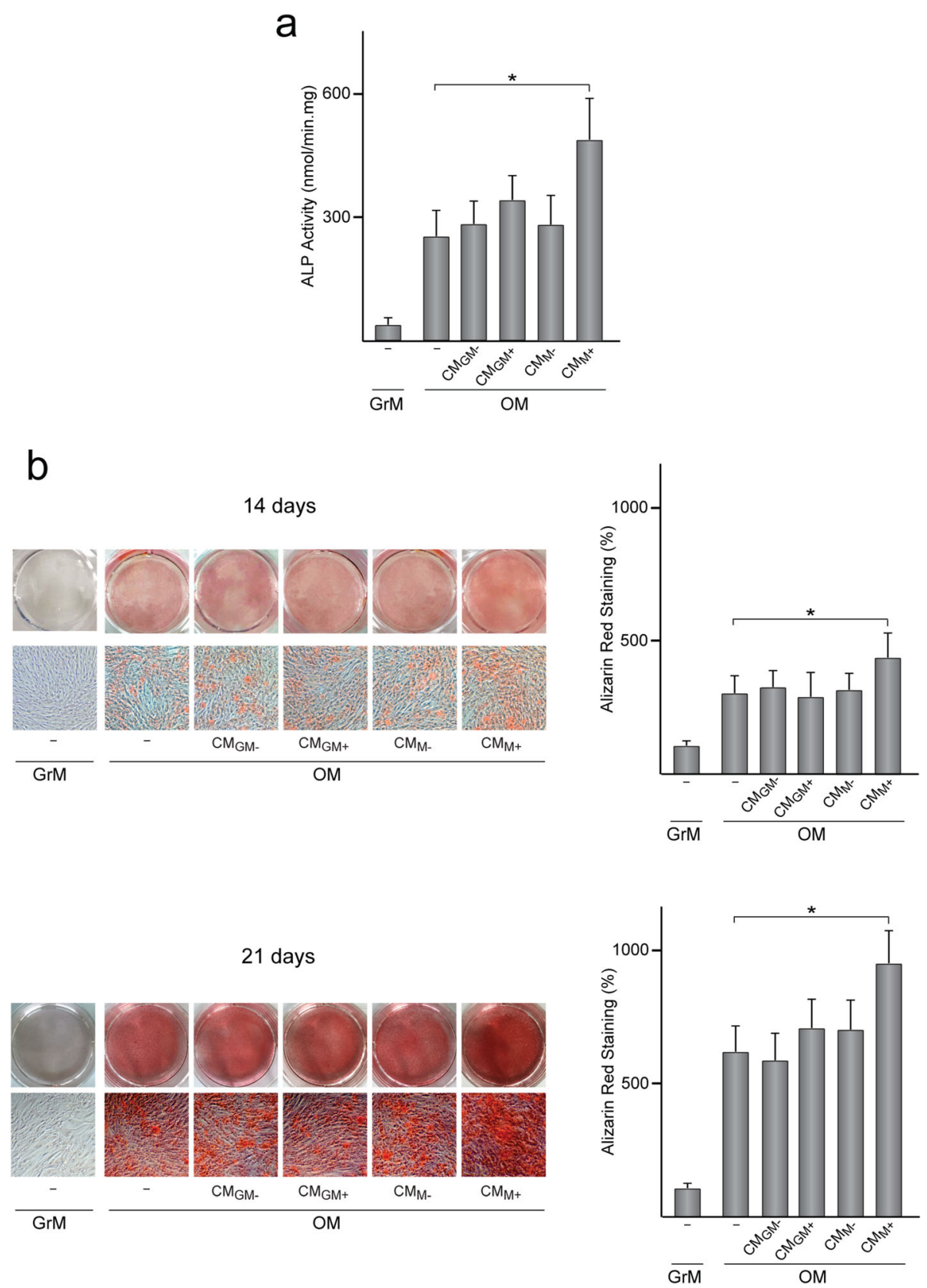

Fig. 3 Osteogenic activity of MSC treated with CM. a ALP activity in MSC treated or not (-) for $48 \mathrm{~h}$ with CM from $M \Phi_{G M}$ and $M \Phi_{M}$ activated $\left(\mathrm{CM}_{\mathrm{GM}+}\right.$ and $\mathrm{CM}_{\mathrm{M}_{+}}$, respectively) or not $\left(\mathrm{CM}_{\mathrm{GM}-}\right.$ and $\mathrm{CM}_{\mathrm{M}_{-}}$, respectively) with LPS and further incubated in osteogenic medium (OM) for 14 days. b. Alizarin red staining and quantification in MSC treated or not with CM from macrophages and further incubated in OM for 14 days (upper panel) or 21 days (lower panel). Data in b are relative to those measured in untreated MSC incubated in growth medium (GrM), which were given an arbitrary value of $100 .{ }^{*} p<0.05$ between the indicated conditions

whereas neutralization of IL-10 led to the opposite effect (Fig. 5a). ALPL mRNA levels in MSC, which remained unaffected by treatment with $\mathrm{CM}_{\mathrm{M}+}$, were reduced when TNF- $\alpha$ or IL-10 was neutralized (Fig. 5a). Blocking TNF- $\alpha$ or IL-10 led to a decrease in ALP activity of MSC treated with $\mathrm{CM}_{\mathrm{M}+}$ and further incubated in osteogenic medium (Fig. 5b). In contrast, the formation of mineralized nodules by MSC treated with $\mathrm{CM}_{\mathrm{M}_{+}}$decreased by blocking IL-10 but not TNF- $\alpha$ (Fig. $5 \mathrm{c}$ ). It should be noted that blocking TNF- $\alpha$ or IL-10 in $\mathrm{CM}_{\mathrm{GM}+}$ had no effect on MSC osteogenesis (Additional file 1: Figure S3). These data indicate that TNF- $\alpha$ and IL-10 secreted by anti-inflammatory macrophages regulate MSC osteogenic activity. 
a
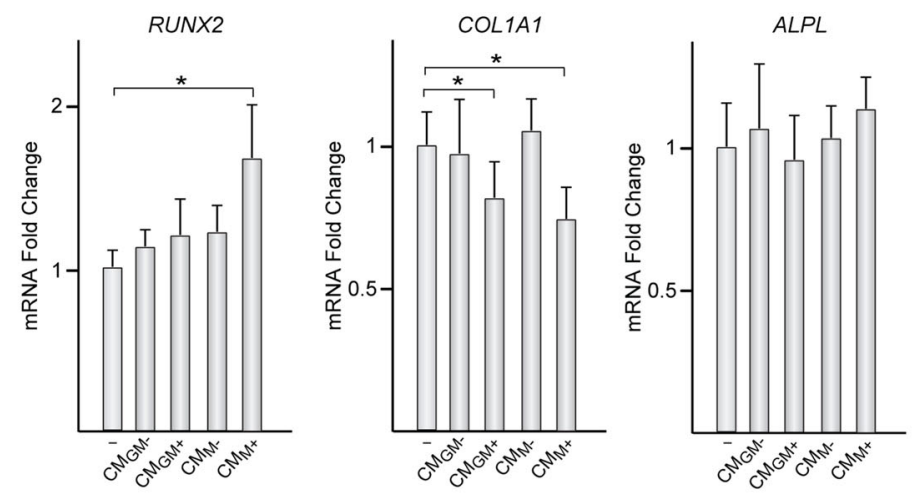

b

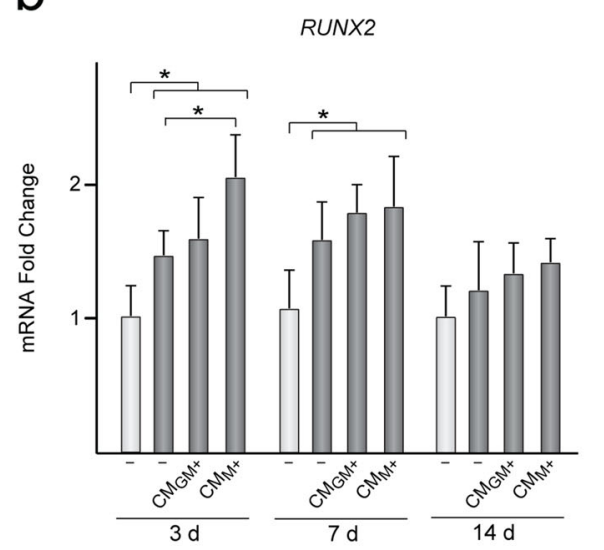

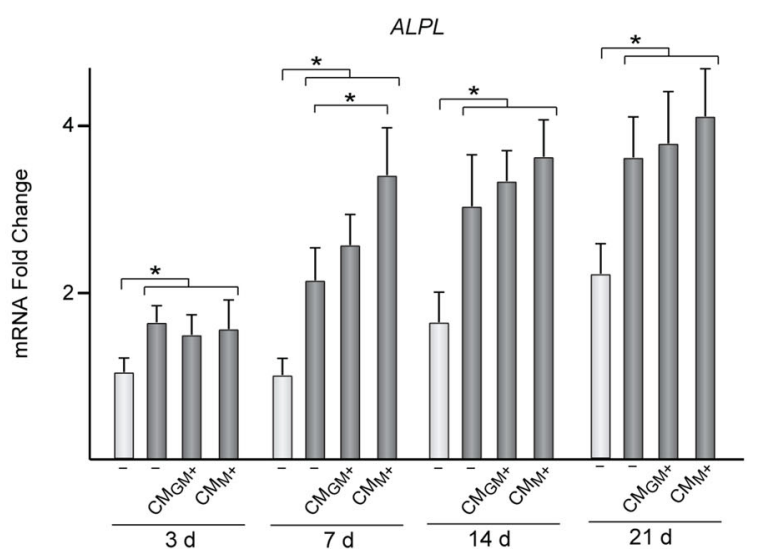

Fig. 4 Expression of bone-related genes in MSC treated with CM. a RUNX2, COL1A1, and ALPL mRNA levels in MSC treated or not (-) for $48 \mathrm{~h}$ with $C M$ from $M \Phi_{G M}$ and $M \Phi_{M}$ activated $\left(C M_{G M+}\right.$ and $C M_{M+}$, respectively) or not $\left(C M_{G M-}\right.$ and $C M_{M-}$, respectively) with LPS. Data are relative to those measured in untreated MSC, which were given an arbitrary value of 1. b RUNX2, COL1A1, and ALPL mRNA levels in MSC treated or not (-) for $48 \mathrm{~h}$ with $\mathrm{CM}_{\mathrm{GM}+}$ or $\mathrm{CM}_{\mathrm{M}+}$ and further incubated in osteogenic medium (dark gray) for the indicated time points. Data are relative to those measured in untreated MSC incubated in growth medium (light gray) for 3 days, which were given an arbitrary value of $1 .{ }^{*} p<0.05$ between the indicated conditions

\section{MSC response to treatment with TNF- $a$ or IL-10}

To further investigate the effect of TNF- $\alpha$ and IL-10 on MSC osteogenesis, MSC were treated for $48 \mathrm{~h}$ with 0.1 , 1 , or $10 \mathrm{ng} / \mathrm{ml} \mathrm{TNF- \alpha}$ or IL-10 and mRNA levels of RUNX2, COL1A1, and ALPL were quantified (Fig. 6a).
RUNX2 transcript levels increased only when MSC were treated with $1 \mathrm{ng} / \mathrm{ml}$ IL-10. COL1A1 mRNA levels decreased after treating MSC with TNF- $\alpha$ at 1 or $10 \mathrm{ng} / \mathrm{ml}$ while IL-10 had no effect at any tested dose. The effects of IL-10 or TNF- $\alpha$ on ALPL expression were dependent 


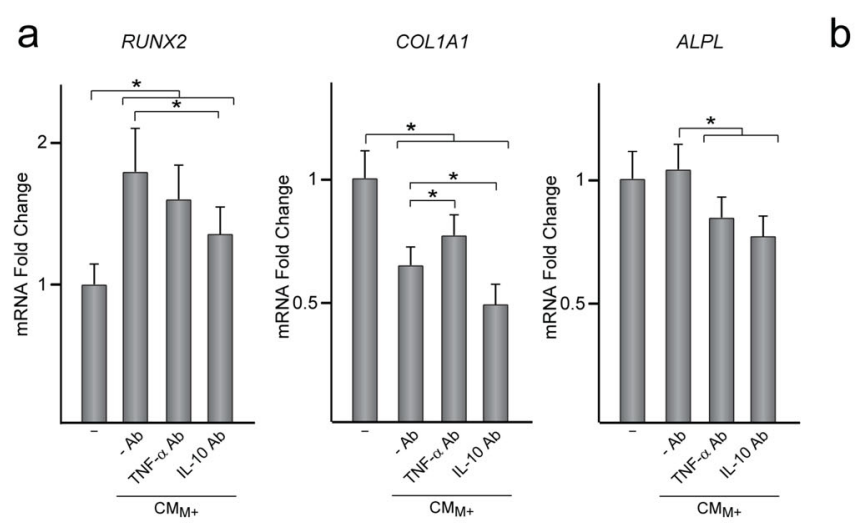

b

C
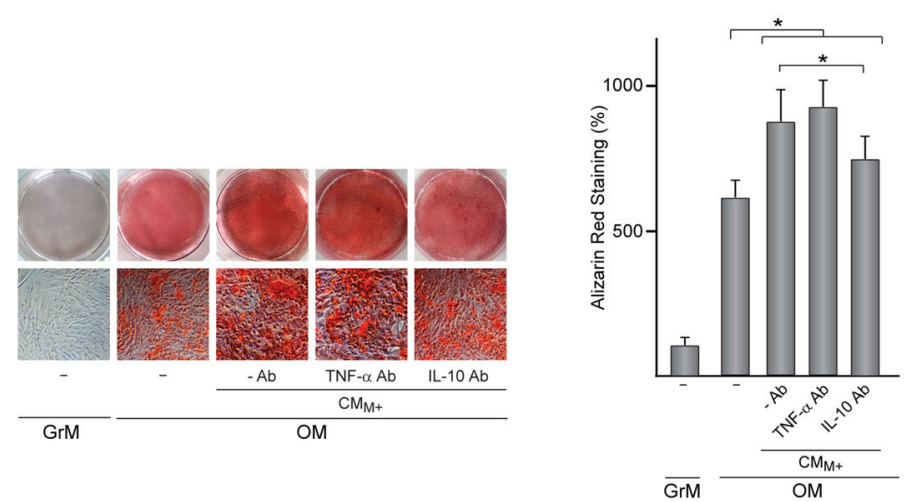

Fig. 5 Involvement of TNF-a and IL-10 in the osteogenic activity of MSC treated with CM from anti-inflammatory macrophages. a RUNX2, COL1A1 and ALPL mRNA levels in MSC treated or not (-) for $48 \mathrm{~h}$ with $\mathrm{CM}_{\mathrm{M}+}$ that had been incubated or not (-Ab) with TNF-a or IL-10 neutralizing antibody (Ab). Data are relative to those measured in untreated MSC, which were given an arbitrary value of 1. ALP activity (b) and alizarin red staining and quantification (c) in MSC treated or not with $\mathrm{CM}_{\mathrm{M}_{+}}$and further incubated in osteogenic medium (OM) for 14 (b) or 21 (c) days. Data in $\mathbf{c}$ are relative to those measured in untreated MSC incubated in growth medium (GrM), which were given an arbitrary value of $100 .{ }^{*} p<0.05$ between the indicated conditions

on the assayed dose. ALPL mRNA levels in MSC remained unaffected by treatment with IL-10 at the lowest dose while increased when IL-10 was applied at 1 or $10 \mathrm{ng} / \mathrm{ml}$. TNF- $\alpha$ at $1 \mathrm{ng} / \mathrm{ml}$ also increased ALPL mRNA levels in MSC whereas it had no effect at 0.1 or $10 \mathrm{ng} /$ $\mathrm{ml}$. Treatment with TNF- $\alpha$ or IL-10 at $1 \mathrm{ng} / \mathrm{ml}$ increased ALP activity of MSC incubated under osteogenic conditions, which further increased by IL-10 at $10 \mathrm{ng} / \mathrm{ml}$ (Fig. 6b). In addition, mineralized nodule formation in MSC layers increased after treatment with $1 \mathrm{ng} / \mathrm{ml}$ TNF$\alpha$ and further increased with IL-10 at 1 or $10 \mathrm{ng} / \mathrm{ml}$ (Fig. 6c). Treatment of MSC with IL-10 or TNF- $\alpha$ at the lowest dose or with $10 \mathrm{ng} / \mathrm{ml}$ TNF- $\alpha$ had no effect on MSC osteogenic differentiation (Fig. 6b, c). As incubation of MSC with CM from macrophages enhances MSC adhesion and migration (Fig. 2a, c), we finally evaluated whether TNF- $\alpha$ and IL-10, at doses that enhance osteogenesis, also modulate these processes. MSC treated with cytokines displayed an elongated or irregularly polygonal shape, similar to that observed in untreated cells (Fig. 7a). In fact, the average elongation ratio of MSC untreated and treated with cytokines was similar (Fig. 7b). MSC attachment was unaffected by treatment with $\mathrm{IL}-10$ at $10 \mathrm{ng} / \mathrm{ml}$ (Fig. 7c). In contrast, MSC treated with TNF- $\alpha$ or IL- 10 at $1 \mathrm{ng} / \mathrm{ml}$ attached at a higher extent than untreated MSC (Fig. 7c). Treatment with TNF- $\alpha$ and IL-10 did not affect MSC viability (Fig. 7d). As observed for cell attachment, MSC migration increased upon treatment with TNF- $\alpha$ or IL-10 at 1 $\mathrm{ng} / \mathrm{ml}$ (Fig. 7e). Together, these data indicate that treatment with TNF- $\alpha$ and IL-10 at $1 \mathrm{ng} / \mathrm{ml}$ enhances MSC adhesion, migration and osteogenesis.

\section{Discussion}

Macrophages play a key role during bone healing, participating in both initial inflammatory response and early anabolic phase of repair [1]. Phenotypic switching of macrophages during fracture healing leads to temporally controlled release of inflammatory mediators [26]. While the prominent contribution of inflammatory factors to fracture healing is well established, their direct effects on osteogenic precursors are not fully understood. Having recently shown that factors 
a

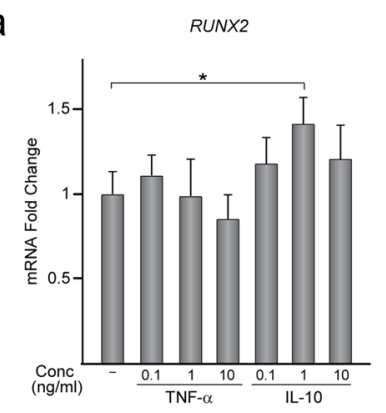

COL1A1

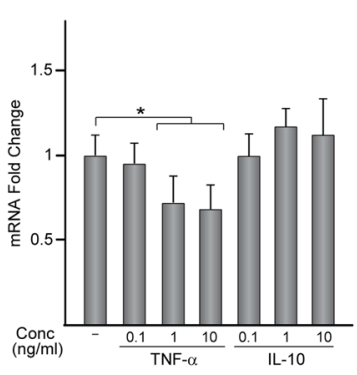

ALPL

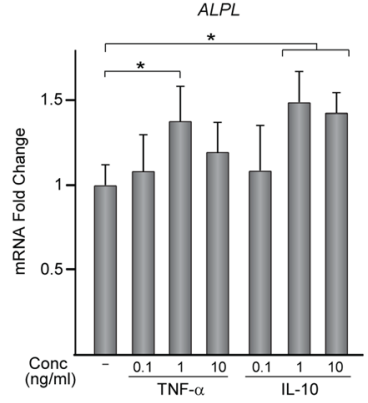

b

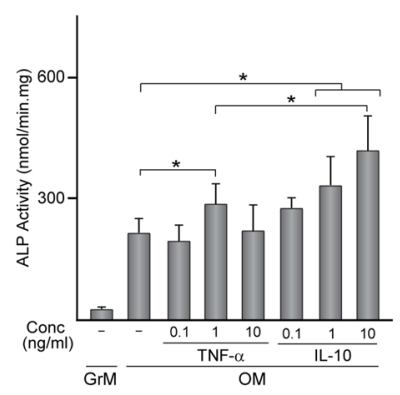

C
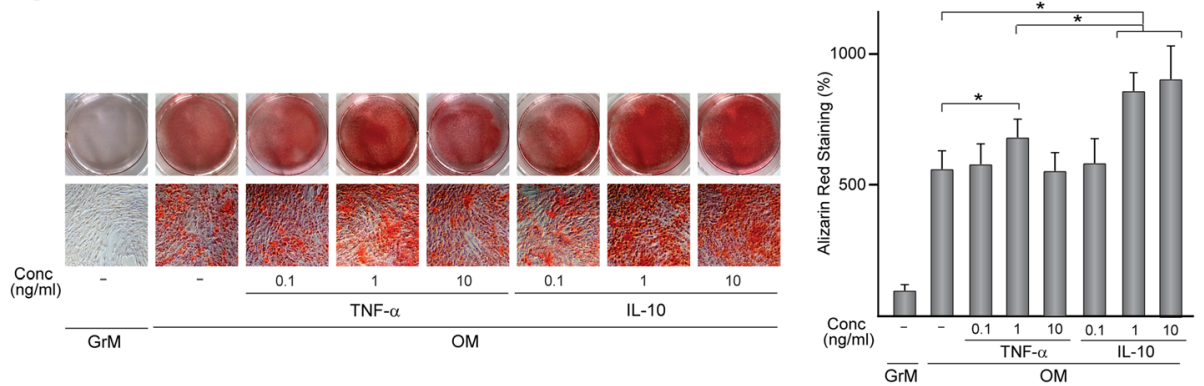

Fig. 6 Osteogenic activity of MSC treated with TNF-a or IL-10. a RUNX2, COL1A1 and ALPL mRNA levels in MSC treated or not (-) for 48 h with TNF-a or IL-10 at $0.1,1$, or $10 \mathrm{ng} / \mathrm{ml}$. Data are relative to those measured in untreated MSC, which were given an arbitrary value of 1 . ALP activity (b) and alizarin red staining and quantification (c) in MSC treated or not with TNF-a or IL-10 and further incubated in osteogenic medium (OM) for 14 (b) or 21 (c) days. Data in c are relative to those measured in untreated MSC incubated in growth medium (GrM), which were given an arbitrary value of $100 .{ }^{*} p<0.05$ between the indicated conditions

originated from pro-inflammatory and anti-inflammatory macrophages enhance MSC immunoregulatory properties [18], data herein provide evidence that MSC adhesion, migration, and osteogenic potential are also regulated by the inflammatory environment. Inflammatory cytokines influence focal adhesion assembly and cytoskeleton rearrangement, which regulate cell adhesion and migration [27, 28]. MSC treated with $\mathrm{CM}$ from activated macrophages elongated as a result of a more parallel arrangement of actin bundles. Cell morphological elongation has been associated with an increased migration rate [29]. In this regard, migratory activity was higher in MSC treated with $\mathrm{CM}_{\mathrm{GM}_{+}}$or $\mathrm{CM}_{\mathrm{M}_{+}}$than with $\mathrm{CM}$ from non-activated macrophages, supporting the involvement of inflammatory cytokines in MSC mobilization. In fact, treatment with TNF- $\alpha$ or IL-10 enhanced MSC ability to attach and migrate, although to a lesser extent than
$\mathrm{CM}$ from activated macrophages. Of note, $\mathrm{CM}_{\mathrm{GM}_{+}}$increased MSC elongation, attachment, and migration to a higher extent than $\mathrm{CM}_{\mathrm{M}+}$, suggesting that pro-inflammatory factors that participate in the early inflammatory response enhance MSC mobilization to injured sites. It should be mentioned that no obvious differences in cell elongation were noted between differentiating MSC treated with $\mathrm{CM}$ and untreated MSC (Additional file 1: Figure S2), indicating that the effect of $\mathrm{CM}$ on cell morphology was rapidly lost in osteogenic medium.

The role of macrophage-derived factors in MSC osteogenesis remains controversial, mainly due to differences in experimental setups used to study it [30]. Previous studies have reported that the treatment of MSC with media conditioned by pro-inflammatory macrophages increases RUNX2 and ALPL mRNA levels [31] as well as cell layer 
a

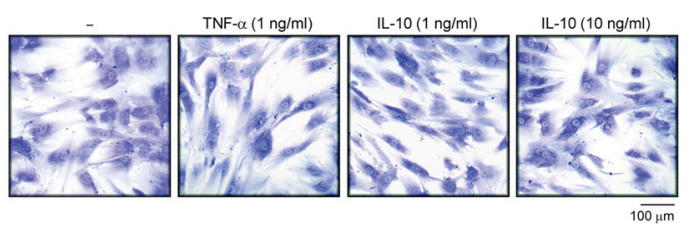

C

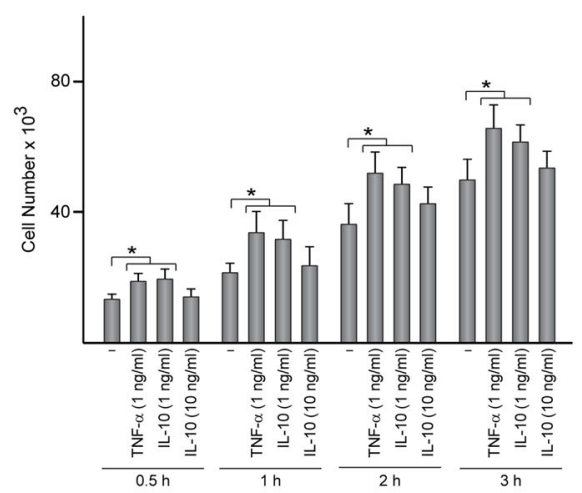

d b

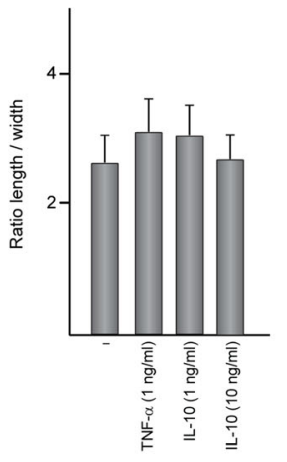

e
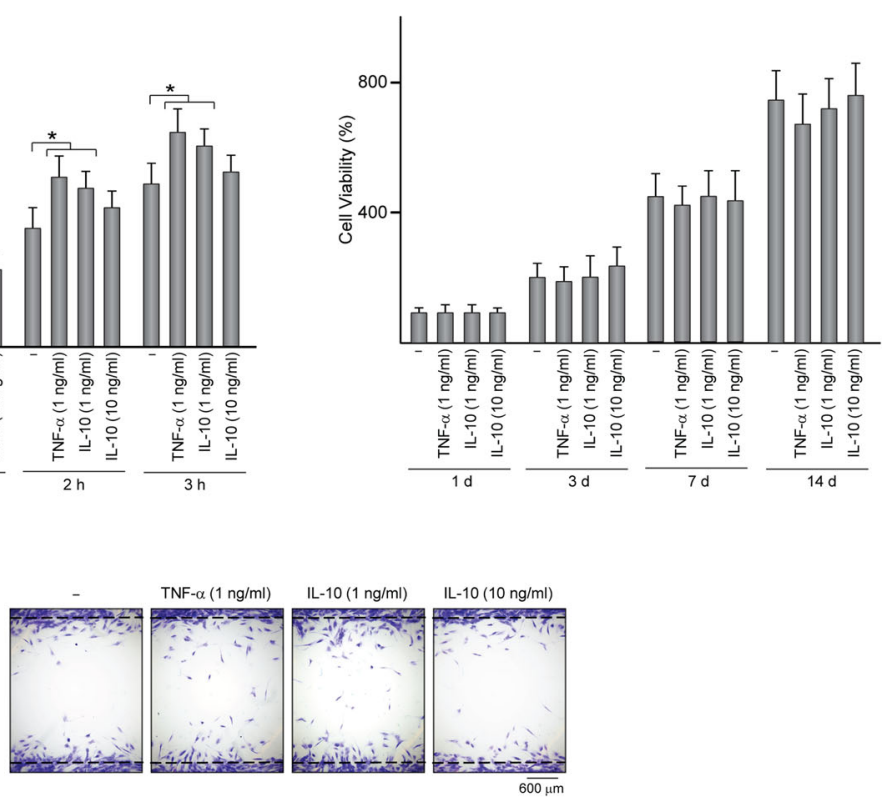

Fig. 7 Morphology, adhesion, viability, and migration of MSC treated with TNF-a or IL-10. a Optical microscope images showing the morphology of MSC treated or not (-) for $48 \mathrm{~h}$ with the indicated doses of TNF-a or IL-10, after crystal violet staining. $\mathbf{b}$ Ratio of cell length to width as a measure of cell elongation. c Number of MSC treated or not with TNF-a or IL-10 and incubated in growth medium (GrM) for the indicated time points. $\mathbf{d}$ Viability of MSC treated or not with TNF-a or IL-10 and further incubated in GrM for the indicated time points. The data are relative to those measured in each group on day 1, which were given an arbitrary value of 100. e Migration capacity of MSC seeded inside the area confined by squared silicone barriers, treated or not with TNF-a or IL-10 and allowed to migrate for 5 days. Optical microscope images of cells stained with crystal violet. ${ }^{*} p<0.05$ between the indicated conditions

mineralization [32]. However, we found that the treatment of MSC with $\mathrm{CM}_{\mathrm{GM}+}$ did not result in increased MSC osteogenic differentiation. A plausible explanation for this discrepancy is that MSC osteogenesis was conducted in our experiments in the absence of LPS whereas the previous studies used CM containing LPS as stimulus. LPS regulates MSC osteogenic differentiation, as treatment of MSC with TNF- $\alpha$ plus LPS, but not with TNF- $\alpha$ only, enhanced ALP activity and cell layer mineralization [22]. Unlike M1-like phenotype, murine bone marrow macrophages [33] and THP-1 cells [34] polarized to an M2-like phenotype release factors that enhance MSC osteogenic differentiation, as observed in co-cultures that allow the exchange of soluble factors without direct cell contact. In line with these data, we observed enhanced ALP activity in MSC treated with factors secreted by human anti-inflammatory macrophages at 14 days of differentiation. Enhanced mineralized nodule formation was also detected at this time, indicating earlier calcium deposition to the matrix in MSC after exposure to $\mathrm{CM}_{\mathrm{M}+}$. Therefore, factors secreted by pro-resolving macrophages during the resolution of inflammation might contribute to create a more favorable environment for MSC osteogenesis than those released by pro-inflammatory macrophages at the early stage of inflammation.

Inflammatory cytokines secreted by macrophages contribute to bone formation, as injection of low-doses of TNF- $\alpha$ at the fracture site accelerated bone healing in mice [19]. Investigations into the role of TNF- $\alpha$ on 
osteogenic differentiation of stromal cells have been mainly conducted using recombinant proteins. In the present study, we show that TNF- $\alpha$ produced by macrophages regulates MSC osteogenic potential. Culture of MSC with $\mathrm{CM}_{\mathrm{M}_{+}}$incubated with a blocking anti-TNF- $\alpha$ antibody attenuated the initial phase of osteogenesis, as ALP induction was partially inhibited, whereas blocking TNF- $\alpha$ in $\mathrm{CM}_{\mathrm{GM}+}$ did not affect MSC osteogenic ability. These data suggest that TNF- $\alpha$ may exert osteogenic effects at the onset of the resolution, when its levels start to decrease. Interestingly, exposure of MSC to $1 \mathrm{ng} / \mathrm{ml}$ TNF- $\alpha$ increased ALP activity whereas $10 \mathrm{ng} / \mathrm{ml}$ TNF- $\alpha$ had no effect on MSC osteogenic differentiation. It is worth mentioning that $1 \mathrm{ng} / \mathrm{ml}$ TNF- $\alpha$ is actually close to the mean concentration, of about $700 \mathrm{pg} / \mathrm{ml}$, detected in serum samples from fracture hematomas of patients within $72 \mathrm{~h}$ post-injury [35].

The influence of pro-resolving mediators on MSC osteogenesis remains poorly understood. Phenotypic switching of macrophages during fracture repair leads to the production of IL-10, found in serum samples from fracture hematomas of patients at concentrations around $1 \mathrm{ng} / \mathrm{ml}$ [36]. A recent study showed that recombinant IL-10 can enhance MSC osteogenesis via the $\mathrm{p} 38 / \mathrm{mitogen}$-activated protein kinase (MAPK) signaling pathway [25]. To our knowledge, our study is the first to demonstrate that IL-10 secreted by macrophages regulates MSC osteogenic differentiation. $\mathrm{CM}_{\mathrm{GM}+}$ contained very low levels of IL-10, which had no effect on MSC osteogenesis. However, significant IL-10 levels secreted by anti-inflammatory macrophages enhanced MSC osteogenic ability, as blocking IL-10 led to a reduction in ALP activity and mineralization in MSC treated with $\mathrm{CM}_{\mathrm{M}+}$. Experiments in which MSC were treated with recombinant cytokines revealed that IL-10 was indeed more effective in promoting matrix mineralization than TNF- $\alpha$. In addition to promote MSC osteogenesis, IL-10 enhanced MSC attachment and migration at a dose of $1 \mathrm{ng} / \mathrm{ml}$ but not at $10 \mathrm{ng} /$ $\mathrm{ml}$, suggesting that MSC functions could be tightly regulated by anti-inflammatory mediators in the resolution of inflammation. It should be noted that the effects of TNF- $\alpha$ and IL10 on in vitro MSC osteogenesis likely depend on the length of their application, being pro-osteogenic after short-term treatment, as in the present study, or inhibitory after continuous exposure $[23,25]$. Based on our observations, we speculate that the controlled release of inflammatory signals by macrophages after injury could promote MSC osteogenesis. However, exacerbated and/or sustained proinflammatory response could lead to chronic inflammation and tissue destruction whereas excessive anti-inflammatory macrophage activation could promote fibrosis and abnormal extracellular matrix deposition.

Our data support the involvement of RUNX2 in early stages of osteogenesis, as incubation of MSC in osteogenic medium for 3 days increased RUNX2 mRNA levels. A recent study showed that, in the absence of classic osteogenic inducers, treatment of mouse mesenchymal precursors with cytokines like IL-13 or IL-17A increased the expression of RUNX2, at the protein level, and induced osteoblast differentiation [37]. Our data support the role of cytokines in regulating RUNX2, as treatment of MSC with $\mathrm{CM}_{\mathrm{M}_{+}}$for $48 \mathrm{~h}$ increased RUNX2 mRNA levels, an effect partially mediated by IL-10. MSC treated with recombinant $\mathrm{IL}-10$ at $1 \mathrm{ng} / \mathrm{ml}$ showed higher $R U N X 2$ mRNA levels than untreated cells, supporting the role of IL-10 in promoting MSC osteogenesis. No significant changes in ALPL expression were observed in MSC immediately after treatment with $\mathrm{CM}_{\mathrm{M}+}$. However, exposure to factors released by anti-inflammatory macrophages enhanced ALPL expression in early differentiating MSC, as MSC treated with $\mathrm{CM}_{\mathrm{M}+}$ and incubated in osteogenic media for 7 days showed higher ALPL mRNA levels than untreated cells. COL1A1 is related to the proliferation period and its expression decreases when differentiation starts. mRNA levels of COL1A1, which contains RUNX2 binding sites in its promoter [38], decreased after treating MSC with $\mathrm{CM}_{\mathrm{M}_{+}}$, suggesting further layers of transcriptional regulation. In this regard, TNF- $\alpha$ is known to reduce collagen type I expression [39]. In fact, the culture of MSC with $\mathrm{CM}_{\mathrm{M}+}$ incubated with anti-TNF- $\alpha$ increased COL1A1 mRNA levels and treatment of MSC with TNF- $\alpha$ at 1 or $10 \mathrm{ng} / \mathrm{ml}$ decreased COL1A 1 expression. Interestingly, COL1A1 mRNA levels in MSC treated with $\mathrm{CM}_{\mathrm{M}+}$ decreased when IL-10 was blocked, indicating that IL-10 and TNF- $\alpha$ in $\mathrm{CM}_{\mathrm{M}+}$ have opposite effects on COL1A1 expression. These results suggest that a correct balance between pro- and anti-inflammatory cytokines is necessary for successful collagen matrix deposition after bone injury. Of note, treatment of MSC with IL-10 only did not alter COL1A1 mRNA levels at any tested dose, which indicated that other factors secreted by anti-inflammatory macrophages cooperate with IL10 in the regulation of COL1A1 expression.

In summary, data in this study support the hypothesis that inflammatory environment promotes MSC osteogenesis at the onset of resolution rather than at the early stage of inflammation, which is more favorable for MSC recruitment. We have demonstrated that IL-10 secreted by antiinflammatory macrophages potentiates MSC osteogenesis by increasing the initial phase of matrix maturation as well as mineralization. In addition, IL-10 enhances MSC ability to attach and migrate, which in turn may contribute to bone formation. It should be noted that, in addition to TNF- $\alpha$ and IL-10, CM may contain a large range of soluble factors that could contribute to regulate MSC osteogenesis. Current efforts to augment bone repair involve the use of cytokines for local administration at the fracture site or for priming protocols before MSC implantation [40, 41]. Data herein provide new insights into how cytokines in different inflammatory environments modulate MSC osteogenesis, which may be helpful to develop effective bone regeneration strategies. 


\section{Conclusions}

Factors secreted by pro-inflammatory or anti-inflammatory macrophages increased MSC attachment and migration. These effects were more pronounced when MSC were treated with media from pro-inflammatory macrophages. MSC osteogenic activity was enhanced by factors released by anti-inflammatory macrophages, but not by proinflammatory macrophages. We found that IL-10 originated from anti-inflammatory macrophages increased MSC osteogenic differentiation and regulated the expression of osteogenic markers. In addition, IL-10 potentiated the MSC ability to attach and migrate. These findings contribute to the understanding of the mechanisms by which phenotypic switching of macrophages during bone repair influences MSC osteogenesis and migration.

\section{Supplementary information}

Supplementary information accompanies this paper at https://doi.org/10. 1186/s13287-020-1578-1.

\begin{abstract}
Additional file 1: Figure S1. ALP activity in MSC treated for 24, 72 or $96 \mathrm{~h}$ with $C M$ from MФGM and MФM activated (CMGM+ and CMM+, respectively) or not (CMGM- and CMM-, respectively) with LPS and further incubated in osteogenic medium (OM) for 14 days. Untreated MSC (-) were incubated in growth medium (GrM) or OM for 14 days. ${ }^{*} p<0.05$ between the indicated conditions. Figure S2. Alizarin Red S staining in MSC treated with CM from MDGM and MФM activated (CMGM+ and CMM+, respectively) or not (CMGM- and CMM-, respectively) with LPS and further incubated in osteogenic medium (OM) for 3 or 7 days. Untreated MSC (-) were incubated in growth medium (GrM) or OM for 3 or 7 days. Figure S3. Involvement of TNF-a and IL-10 in the osteogenic activity of MSC treated with CM from pro-inflammatory macrophages. MSC were treated or not (-) for $48 \mathrm{~h}$ with $C M G M+$ that had been incubated or not ( $-\mathrm{Ab}$ ) with TNF-a or IL-10 neutralizing antibody (Ab). ALP activity (a) and alizarin Red $\mathrm{S}$ staining and quantification (b) in MSC treated or not with CMGM+ and further incubated in OM for 14 (a) or 21 (b) days. Data in b are relative to those measured in untreated MSC incubated in growth medium (GrM), which were given an arbitrary value of 100 .
\end{abstract}

\section{Abbreviations}

ALP: Alkaline phosphatase; CM: Conditioned medium; $\mathrm{CM}_{\mathrm{GM}-}$ : $\mathrm{CM}$ from nonactivated $M \Phi_{\mathrm{GM}} ; \mathrm{CM}_{\mathrm{GM}+}$ : $C M$ from $L P S$-activated $M \Phi_{\mathrm{GM}} ; \mathrm{CM}_{\mathrm{M}-}$ : $C M$ from nonactivated $M \Phi_{M} ; C_{M+}$ : CM from LPS-activated $M \Phi_{M} ; C O L 1 A 1$ : Collagen type I alpha 1; FBS: Fetal bovine serum; GM-CSF: Granulocyte macrophage colonystimulating factor; IL: Interleukin; LPS: Lipopolysaccharide; MCP-1: Monocyte chemoattractant protein-1; M-CSF: Macrophage colony-stimulating factor; MSC: Mesenchymal stem cells; $M \Phi_{G M}$ : GM-CSF-generated macrophages; $M \Phi_{M}$ : M-CSF-generated macrophages; PBMC: Peripheral blood mononuclear cells; PBS: Phosphate-buffered saline; RUNX2: Runt-related transcription factor 2; TNF-a: tumor necrosis factor-alpha

\section{Acknowledgements}

We are indebted to the Cell Culture and Image Facilities of the Hospital Universitario La Paz-IdiPAZ for technical help.

\section{Authors' contributions}

GV was responsible for the assembly and interpretation of data and manuscript writing. FB and LMP conducted the experiments. EGC critically reviewed the manuscript. NV contributed to the interpretation of data, manuscript writing, and financial support. LS was responsible for the conception and design, data analysis, financial support, and manuscript writing. All authors read and approved the final manuscript.

\section{Funding}

This work was supported by grants PI15/00752 and PI15/01118 from Instituto de Salud Carlos III (ISCIII)-Fondo Europeo de Desarrollo Regional (FEDER)Ministerio de Economía y Competitividad (MINECO)-AES, grant PI18/00643 from ISCIII-FEDER, Ministerio de Ciencia, Innovación y Universidades (MICINN)-AES and grant RTI2018-095159-B-I00 from MICINN. L.M.P is supported by a predoctoral contract (PEJD-2018-PRE/BMD-7965) from the Comunidad de Madrid (CAM). L.S is supported by a Miguel Servet contract (CPII16/00038) from ISCIIIFEDER-MINECO-AES- FSE. N.V is supported by Program 12 from CAM.

\section{Availability of data and materials}

The datasets generated and/or analyzed during the current study are available from the corresponding author on reasonable request.

\section{Ethics approval and consent to participate}

The protocol of this study was reviewed and approved by the Human Research Committee of Hospital Universitario La Paz (date of approval: 03/ 06/2015). All experiments were carried out in accordance with the approved guidelines and regulations.

\section{Consent for publication}

Not applicable.

\section{Competing interests}

The authors declare that they have no competing interests.

\section{Author details}

${ }^{1}$ Hospital Universitario La Paz. IdiPAZ, Paseo de la Castellana 261, 28046 Madrid, Spain. ${ }^{2}$ Centro de Investigación Biomédica en Red de Bioingeniería, Biomateriales y Nanomedicina, CIBER-BBN, Madrid, Spain. ${ }^{3}$ Departamento de Cirugía Ortopédica y Traumatología, Hospital Universitario La Paz-IdiPAZ, Madrid, Spain

Received: 2 August 2019 Revised: 4 December 2019 Accepted: 3 February 2020 Published online: 13 February 2020

\section{References}

1. Raggatt $L$, Wullschleger ME, Alexander KA, Wu ACK, Millard SM, Kaur S, et al. Fracture healing via periosteal callus formation requires macrophages for both initiation and progression of early endochondral ossification. Am J Pathol. 2014;184(12):3192-204.

2. Alexander KA, Chang MK, Maylin ER, Kohler T, Müller R, Wu AC, et al. Osteal macrophages promote in vivo intramembranous bone healing in a mouse tibial injury model. J Bone Miner Res. 2011;26(7):1517-32.

3. Karnes JM, Daffner SD, Watkins CM. Multiple roles of tumor necrosis factoralpha in fracture healing. Bone. 2015;78:87-93.

4. Gerstenfeld LC, Cho TJ, Kon T, Aizawa T, Tsay A, Fitch J, et al. Impaired fracture healing in the absence of TNF-alpha signaling: the role of TNF-alpha in endochondral cartilage resorption. J Bone Miner Res. 2003;18(9):1584-92.

5. Dresner-Pollak R, Gelb N, Rachmilewitz D, Karmeli F, Weinreb M. Interleukin 10-deficient mice develop osteopenia, decreased bone formation, and mechanical fragility of long bones. Gastroenterology. 2004;127(3):792-801.

6. Kang JS, Suh YJ, Moon KH, Park JS, Roh TH, Park MH, et al. Clinical efficiency of bone marrow mesenchymal stem cell implantation for osteonecrosis of the femoral head: a matched pair control study with simple core decompression. Stem Cell Res Ther. 2018;9(1):1-9.

7. Ansboro S, Roelofs AJ, De Bari C. Mesenchymal stem cells for the management of rheumatoid arthritis. Curr Opin Rheumatol. 2017;29(2):201-7.

8. Liu Z, Yuan X, Liu M, Fernandes G, Zhang Y, Yang S, et al. Antimicrobial peptide combined with BMP2-modified mesenchymal stem cells promotes calvarial repair in an osteolytic model. Mol Ther. 2018;26(1):199-207.

9. Watanabe Y, Harada N, Sato K, Abe S, Yamanaka K, Matushita T. Stem cell therapy: is there a future for reconstruction of large bone defects? Injury. 2016;47:S47-51.

10. Killington K, Mafi R, Mafi P, Khan WS. A systematic review of clinical studies investigating mesenchymal stem cells for fracture non-union and bone defects. Curr Stem Cell Res Ther. 2018;13(4):284-91.

11. Bernardo ME, Fibbe WE. Mesenchymal stromal cells: sensors and switchers of inflammation. Cell Stem Cell. 2013;13(4):392-402.

12. Mankani MH, Kuznetsov SA, Wolfe RM, Marshall GW, Robey PG. In vivo bone formation by human bone marrow stromal cells: reconstruction of the mouse calvarium and mandible. Stem Cells. 2006;24(9):2140-9. 
13. Corn DJ, Kim Y, Krebs MD, Mounts T, Molter J, Gerson S, et al. Imaging early stage osteogenic differentiation of mesenchymal stem cells. J Orthop Res. 2013;31(6):871-9

14. Chu W, Gan Y, Zhuang Y, Wang X, Zhao J, Tang T, et al. Mesenchymal stem cells and porous $\beta$-tricalcium phosphate composites prepared through stem cell screen-enrich-combine(-biomaterials) circulating system for the repair of critical size bone defects in goat tibia. Stem Cell Res Ther. 2018;9(1):157.

15. Kon T, Cho TJ, Aizawa T, Yamazaki M, Nooh N, Graves D, et al. Expression of osteoprotegerin, receptor activator of NF-kappaB ligand (osteoprotegerin ligand) and related proinflammatory cytokines during fracture healing. J Bone Miner Res. 2001;16(6):1004-14

16. Wang $Y, X u$ J, Zhang $X$, Wang $C$, Huang $Y$, Dai $K$, et al. TNF-a-induced LRG1 promotes angiogenesis and mesenchymal stem cell migration in the subchondral bone during osteoarthritis. Cell Death Dis. 2017;8(3):e2715-9.

17. Li W, Ren G, Huang Y, Su J, Han Y, Li J, et al. Mesenchymal stem cells: a double-edged sword in regulating immune responses. Cell Death Differ. 2012;19(9):1505-13.

18. Saldaña L, Bensiamar F, Vallés G, Mancebo FJ, García-rey E, Vilaboa N. Immunoregulatory potential of mesenchymal stem cells following activation by macrophage-derived soluble factors. Stem Cell Res Ther. 2019;6:1-15.

19. Glass GE, Horwood NJ, Freidin A, Nanchahal J, Chan JK, Feldmann M. TNFpromotes fracture repair by augmenting the recruitment and differentiation of muscle-derived stromal cells. Proc Natl Acad Sci. 2011;108(4):1585-90.

20. Lu Z, Wang G, Dunstan CR, Chen Y, Yenn-Ru Lu W, Davies B, et al. Activation and promotion of adipose stem cells by tumour necrosis factor-alpha preconditioning for bone regeneration. J Cell Physiol. 2013;228(8):1737-44.

21. Ueda M, Fujisawa T, Ono M, Hara ES, Pham HT, Nakajima R, et al. A shortterm treatment with tumor necrosis factor-alpha enhances stem cell phenotype of human dental pulp cells. Stem Cell Res Ther. 2014;5(1):1-10.

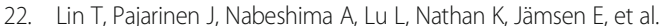
Preconditioning of murine mesenchymal stem cells synergistically enhanced immunomodulation and osteogenesis. Stem Cell Res Ther. 2017:8(1):277.

23. Lacey DC, Simmons PJ, Graves SE, Hamilton JA. Proinflammatory cytokines inhibit osteogenic differentiation from stem cells: implications for bone repair during inflammation. Osteoarthr Cartil. 2009;17(6):735-42.

24. Fiorentino DF, Zlotnik A, Mosmann TR, Howard M, O'Garra A. IL-10 inhibits cytokine production by activated macrophages. J Immunol. 1991;147(11):3815-22.

25. Chen E, Liu G, Zhou X, Zhang W, Wang C, Hu D, et al. Concentrationdependent, dual roles of IL-10 in the osteogenesis of human BMSCs via P38/MAPK and NF-kB signaling pathways. FASEB J. 2018;88:1-13.

26. Wu AC, Raggatt $L$, Alexander KA, Pettit AR. Unraveling macrophage contributions to bone repair. Bonekey Rep. 2013;2:373.

27. Wang Q, Delcorde J, Tang T, Downey GP, McCulloch CA. Regulation of IL-1 signaling through control of focal adhesion assembly. FASEB J. 2018;32(6):3119-32

28. Wójciak-Stothard B, Entwistle A, Garg R, Ridley AJ. Regulation of TNF-alphainduced reorganization of the actin cytoskeleton and cell-cell junctions by rho, Rac, and Cdc42 in human endothelial cells. J Cell Physiol. 1998;176(1):150-65.

29. Pickering JG, Uniyal S, Ford CM, Chau T, Laurin MA, Chow LH, et al. Fibroblast growth factor-2 potentiates vascular smooth muscle cell migration to platelet-derived growth factor: upregulation of alpha2beta1 integrin and disassembly of actin filaments. Circ Res. 1997;80(5):627-37.

30. Pajarinen J, Lin T, Gibon E, Kohno Y, Maruyama M, Nathan K, et al. Mesenchymal stem cell-macrophage crosstalk and bone healing. Biomaterials. 2019;196:80-9.

31. Omar OM, Granéli C, Ekström K, Karlsson C, Johansson A, Lausmaa J, et al. The stimulation of an osteogenic response by classical monocyte activation. Biomaterials. 2011;32(32):8190-204.

32. Guihard P, Danger Y, Brounais B, David E, Brion R, Delecrin J, et al. Induction of osteogenesis in mesenchymal stem cells by activated monocytes/macrophages depends on oncostatin M signaling. Stem Cells. 2012;30(4):762-72.

33. Gong $L$, Zhao $Y$, Zhang $Y$, Ruan $Z$. The macrophage polarization regulates MSC osteoblast differentiation in vitro. Ann Clin Lab Sci. 2016;46(1):65-71.

34. Zhang Y, Böse T, Unger RE, Jansen JA, Kirkpatrick CJ, van den Beucken JJJP. Macrophage type modulates osteogenic differentiation of adipose tissue MSCs. Cell Tissue Res. 2017;369(2):273-86.

35. Hoff $\mathrm{P}$, Gaber T, Strehl C, Jakstadt M, Hoff H, Schmidt-Bleek K, et al. A pronounced inflammatory activity characterizes the early fracture healing phase in immunologically restricted patients. Int J Mol Sci. 2017;18(3):583

36. Hauser CJ, Joshi P, Zhou X, Kregor P, Hardy KJ, Devidas M, et al. Production of interleukin-10 in human fracture soft-tissue hematomas. Shock. 1996;6(1):3-6.
37. Khalmuratova R, Shin H-W, Kim DW, Park J-W. Interleukin (IL)-13 and IL-17A contribute to neo-osteogenesis in chronic rhinosinusitis by inducing RUNX2. EBioMedicine. 2019;46:330-41.

38. Kern B, Shen J, Starbuck M, Karsenty G. Cbfa1 contributes to the osteoblastspecific expression of type I collagen genes. J Biol Chem. 2001;276(10):7101-7.

39. Greenwel P, Tanaka S, Penkov D, Zhang W, Olive M, Moll J, et al. Tumor necrosis factor alpha inhibits type I collagen synthesis through repressive CCAAT/enhancer-binding proteins. Mol Cell Biol. 2000;20(3):912-8.

40. Chan JK, Glass GE, Ersek A, Freidin A, Williams GA, Gowers K, et al. Low-dose TNF augments fracture healing in normal and osteoporotic bone by upregulating the innate immune response. EMBO Mol Med. 2015;7(5):547-61.

41. Aktas E, Chamberlain CS, Saether EE, Duenwald-Kuehl SE, KondratkoMittnacht J, Stitgen M, et al. Immune modulation with primed mesenchymal stem cells delivered via biodegradable scaffold to repair an Achilles tendon segmental defect. J Orthop Res. 2017;35(2):269-80.

\section{Publisher's Note}

Springer Nature remains neutral with regard to jurisdictional claims in published maps and institutional affiliations.

Ready to submit your research? Choose BMC and benefit from:

- fast, convenient online submission

- thorough peer review by experienced researchers in your field

- rapid publication on acceptance

- support for research data, including large and complex data types

- gold Open Access which fosters wider collaboration and increased citations

- maximum visibility for your research: over $100 \mathrm{M}$ website views per year

At BMC, research is always in progress.

Learn more biomedcentral.com/submissions 